\title{
Relationships Among Factors Relevant to Abdominal Fat and Age-Related Hearing Loss
}

\author{
Young Lee ${ }^{1} \cdot$ Mina Park ${ }^{1,2}$ \\ ${ }^{1}$ Department of Otorhinolaryngology-Head and Neck Surgery, Healthcare Research Institute, Seoul National University Hospital Healthcare \\ System Gangnam Center, Seoul; ${ }^{2}$ Department of Translational Biomedical Research, Seoul National University College of Medicine, Seoul, Korea
}

Objectives. Metabolic syndrome is related with abdominal fat and with age-related hearing loss (ARHL). In this study, we evaluated the association between a variety of factors relevant to abdominal fat (FRAs) and hearing thresholds.

Methods. We reviewed retrospectively the medical records of 2,602 subjects aged over 40 years with symmetrical sensorineural hearing loss who underwent abdominal fat computed tomography (CT) scans. Univariate and multivariate linear regression analyses were used to demonstrate the association between each FRA and hearing thresholds at low and high frequencies.

Results. Four of 5 FRAs were associated with hearing thresholds at high frequencies in males. All FRAs examined showed a relationship with hearing thresholds at low frequencies in females. Diabetes mellitus (DM) among clinical factors and visceral adipose tissue (VAT) among the 5 FRAs were the most reflective of hearing thresholds in both males and females.

Conclusion. We found that FRAs were associated with hearing loss with frequency specific characteristics according to sex and reinforced that DM andVAT is particularly an important role for hearing.

Keywords. Hearing Loss; Abdominal Fat; Visceral Fat; Body Mass Index

\section{INTRODUCTION}

Age-related hearing loss (ARHL), also known as presbycusis, is the result of the cumulative effects of aging on hearing. It is characterized by progressive, bilateral, symmetrical sensorineural hearing loss, and results from degeneration of the inner ear (the cochlea) or the auditory nerves. It is the second most common disease, following arthritis, affecting 1 in 3 people $\geq 65$ years, and 1 in 2 people $\geq 75$ years [1]. Moreover, the proportion of the population $\geq 65$ years will continue to increase gradually, and will represent one-quarter of the total population by

\footnotetext{
- Received December 31, 2016

Revised March 24, 2017

Accepted April 13, 2017

- Corresponding author: Mina Park

Department of Otorhinolaryngology-Head and Neck Surgery, Healthcare Research Institute, Seoul National University Hospital Healthcare System Gangnam Center, 152 Teheran-ro, Gangnam-gu, Seoul 06236, Korea Tel: +82-2-2112-5671, Fax: +82-2-2112-5794

E-mail: pimpleboy@naver.com
}

2030 [2]. Thus, ARHL is expected to become a major public health issue in future decades.

Obesity is a primary preventable cause of morbidity and mortality and is on the rise worldwide. Body mass index (BMI) has been widely used to define and classify obesity according to World Health Organization criteria [3]. However, abdominal obesity has been regarded as a more important risk factor than BMI [4]. Abdominal obesity consists of visceral adipose tissue (VAT) and subcutaneous adipose tissue (SAT), the characteristics of which differ in several respects.

Weight, BMI, waist circumference (WC), total adipose tissue (TAT), VAT, and SAT corresponds to factors relevant to abdominal fat (FRAs). Most previous studies that have reported a relationship between obesity and hearing have assessed only 1 of above 6 FRAs, such as BMI [5,6], WC [7], or VAT [8]. To our knowledge, there is only one report showing a relationship between several FRAs and hearing [8]. However, in that study, the sample consisted of 662 adults, which was not sufficient to draw concrete conclusions.

Copyright (C) 2017 by Korean Society of Otorhinolaryngology-Head and Neck Surgery.

This is an open-access article distributed under the terms of the Creative Commons Attribution Non-Commercial License (http://creativecommons.org/licenses/by-nc/4.0)

which permits unrestricted non-commercial use, distribution, and reproduction in any medium, provided the original work is properly cited. 
In this study, we sought to evaluate the relationship between several FRAs and hearing thresholds in a larger sample of adults, aged over 40 years. Moreover, we evaluated which factor among the FRAs was most associated with hearing threshold.

\section{MATERIALS AND METHODS}

\section{Subjects}

Between May 2004 and December 2015, 2,602 subjects $\geq 40$ years (range, 40 to 89 years) of age who attended the Seoul National University Hospital Healthcare System at the Gangnam Center underwent fat measurements by computed tomography (CT), pure tone audiometry for 4 frequencies $(0.5,1,2$, and 4 $\mathrm{kHz}$ ), and examination of the tympanic membrane by otologists. All subjects answered a medical questionnaire and underwent a medical examination. Subjects $(n=31)$ who underwent external or middle ear surgery and/or showed abnormal tympanic membrane findings were excluded; in total, 2,571 subjects (range, 40 to 89 years) were included in the analysis.

This retrospective study was conducted after approval by the Institutional Review Board of the Clinical Research Institute of Seoul National University Hospital (No. 1512-094-728).

\section{Anthropometric measurements}

Each subject's height, weight, and WC were measured after overnight fasting. BMI was calculated by dividing body weight in kilograms by squared height in meters $\left(\mathrm{kg} / \mathrm{m}^{2}\right)$. WC was measured at the level of the mid-point between the inferior border of the ribs and the upper margin of the iliac crest [4].

\section{Measuring the area of abdominal adipose tissue by computed tomography}

We used a standard technique to measure abdominal adipose tissue, as described previously $[9,10]$. Briefly, subjects were scanned in a supine position using a 16-detector CT scanner (Somatom Sensation 16, Siemens AG, Erlangen, Germany). A slice image at the level of the umbilicus, $5 \mathrm{~mm}$ in thickness was used to calculate the abdominal adipose tissue. Using Rapidia 2.8 CT software (Infinitt, Seoul, Korea), the surface area that came within -250 to -50 Hounsfield units was deemed to be abdominal adipose tissue. The TAT andVAT were demarcated by manual tracing with a

\section{H I I G H L L I}

- Factors relevant abdominal fat (FRAs) were correlated with hearing at high frequencies in men.

- In women, FRAs were correlated with hearing at low frequencies.

- Visceral adipose tissue has major implications for hearing. cursor and the difference between TAT and VAT was deemed to be SAT. This was performed by 2 researchers affiliated to Seoul National University Hospital Healthcare System at the Gangnam Center and the mean of 2 values was used for analysis.

\section{Measuring hearing thresholds}

Hearing thresholds were measured at 4 frequencies $(0.5,1,2$, and $4 \mathrm{kHz}$ ) in both ears for each subject in a double-walled sound booth using audiometry (Madsen Itera II, GN Otometrics, Taastrup, Denmark). The average of the thresholds at 0.5 and 1 $\mathrm{kHz}$ was regarded as pure tone audiometry (PTA)-low, and the average at 2 and $4 \mathrm{kHz}$ was regarded as PTA-high.

\section{Classification of the variables}

Weight, BMI,WC,TAT,VAT, and SAT were categorized as FRAs. The other factors-age, sex, height, hypertension (HTN), diabetes mellitus (DM), smoking, and alcohol consumption-were categorized as clinical factors.

\section{Statistical analyses}

Continuous variables are presented as means \pm standard deviations (SDs). Categorical variables are presented as frequencies and percentages. Student $t$-test for continuous variables and chisquare tests for categorical variables were used to compare differences between sexes. We conducted univariate linear regression to identify clinical factors associated with PTA thresholds. The significant clinical factors in univariate analyses and one of the FRAs were then considered as independent variables in a multiple linear regression. A step-wise multiple linear regression analysis was performed to determine the relationships between risk factors and PTA thresholds. The statistical significance level was set at 0.05. 'R' software ver. 3.2.2 (R Foundation for Statistical Computing, Vienna, Austria; http://www.R-project.org) was used for statistical analyses.

\section{RESULTS}

\section{Demographic and anthropometric characteristics}

Subject characteristics are summarized in Table 1. In total, 2,571 subjects ( $n=1,435$ males and $n=1,136$ females) were included in the final analysis. The mean age was $57.6 \pm 7.3$ years (males, $57.5 \pm 7.6$ years; females, $57.8 \pm 7.0$ years) with no significant difference. The mean height, weight, BMI, and WC were $165.0 \pm$ $8.3 \mathrm{~cm}, 65.1 \pm 11.9 \mathrm{~kg}, 23.8 \pm 3.2 \mathrm{~kg} / \mathrm{m}^{2}$, and $85.2 \pm 9.0 \mathrm{~cm}$, respectively, with significant differences between males and females (height, $170.5 \pm 5.8 \mathrm{~cm}$ vs. $158.0 \pm 5.2 \mathrm{~cm}$; weight, $71.6 \pm$ $10.0 \mathrm{~kg}$ vs. $57.0 \pm 8.7 \mathrm{~kg}$; BMI, $24.6 \pm 2.9 \mathrm{~kg} / \mathrm{m}^{2}$ vs. $22.8 \pm 3.2$ $\mathrm{kg} / \mathrm{m}^{2}$; and WC, $88.5 \pm 7.9 \mathrm{~cm}$ vs. $81.2 \pm 8.6 \mathrm{~cm}$; all $P<0.001$ ). For all subjects, the mean PTA-low and PTA-high hearing levels were $16.7 \pm 8.3 \mathrm{~dB} H L$ and $23.4 \pm 13.2 \mathrm{~dB}$ HL, respectively. The PTA-low hearing level did not differ between the sexes. Howev- 
Table 1. Comparisons between male and female subjects regarding to demographic, auditory, and factors relevant abdominal fat

\begin{tabular}{|c|c|c|c|c|}
\hline Variable & $\begin{array}{c}\text { All } \\
(n=2,571)\end{array}$ & $\begin{array}{c}\text { Male } \\
(n=1,435)\end{array}$ & $\begin{array}{l}\text { Female } \\
(n=1,136)\end{array}$ & $P$-value \\
\hline Age (yr) & $57.6 \pm 7.3$ & $57.5 \pm 7.6$ & $57.8 \pm 7.0$ & 0.234 \\
\hline Height (cm) & $165.0 \pm 8.3$ & $170.5 \pm 5.8$ & $158.0 \pm 5.2$ & $<0.001$ \\
\hline Weight (kg) & $65.1 \pm 11.9$ & $71.6 \pm 10.0$ & $57.0 \pm 8.7$ & $<0.001$ \\
\hline BMI $\left(\mathrm{kg} / \mathrm{m}^{2}\right)$ & $23.8 \pm 3.2$ & $24.6 \pm 2.9$ & $22.8 \pm 3.2$ & $<0.001$ \\
\hline$W C(\mathrm{~cm})$ & $85.2 \pm 9.0$ & $88.5 \pm 7.9$ & $81.2 \pm 8.6$ & $<0.001$ \\
\hline PTA-low (dB HL) & $16.7 \pm 8.3$ & $16.8 \pm 8.4$ & $16.6 \pm 8.2$ & 0.435 \\
\hline PTA-high (dB HL) & $23.4 \pm 13.2$ & $26.3 \pm 14.1$ & $19.7 \pm 11.0$ & $<0.001$ \\
\hline TAT $\left(\mathrm{cm}^{2}\right)$ & $292.0 \pm 161.1$ & $290.0 \pm 125.4$ & $294.5 \pm 197.2$ & 0.504 \\
\hline $\operatorname{VAT}\left(\mathrm{cm}^{2}\right)$ & $122.7 \pm 70.4$ & $144.4 \pm 65.2$ & $95.3 \pm 67.2$ & $<0.001$ \\
\hline $\mathrm{SAT}\left(\mathrm{cm}^{2}\right)$ & $169.3 \pm 116.8$ & $145.6 \pm 71.8$ & $199.3 \pm 150.9$ & $<0.001$ \\
\hline HTN & & & & $<0.001$ \\
\hline No & $1,065(77.9)$ & $614(74.2)$ & $451(83.5)$ & \\
\hline Yes & $303(22.1)$ & $214(25.8)$ & $89(16.5)$ & \\
\hline DM & & & & 0.007 \\
\hline No & $1,256(91.9)$ & 746 (90.2) & $510(94.4)$ & \\
\hline Yes & $111(8.1)$ & $81(9.8)$ & $30(5.6)$ & \\
\hline Smoking & & & & $<0.001$ \\
\hline No & 854 (82.3) & $523(75.4)$ & $331(96.2)$ & \\
\hline Yes & $184(17.7)$ & $171(24.6)$ & $13(3.8)$ & \\
\hline Alcohol & & & & $<0.001$ \\
\hline No & $267(18.5)$ & $65(7.4)$ & $202(36.1)$ & \\
\hline Yes & $1,176(81.5)$ & 818 (92.6) & 358 (63.9) & \\
\hline
\end{tabular}

Values are presented as number (\%) or mean \pm standard deviation. BMI, body mass index; WC, waist circumference; PTA-low, hearing thresholds at low frequencies; PTA-high, hearing thresholds at high frequencies; TAT, total adipose tissue; VAT, visceral adipose tissue; SAT, subcutaneous adipose tissue; HTN, hypertension; DM, diabetes mellitus.

er, females had a significantly lower PTA-high hearing level (26.3 $\pm 14.1 \mathrm{~dB}$ HL vs. $19.7 \pm 11.0 \mathrm{~dB}$ HL, $P<0.001)$. VAT was significantly higher in males than in females and SAT was higher in females than in males $(P<0.001)$. Total adipose tissue showed no significant difference between males and females. The incidences of HTN and DM were higher in males than in females $(P<0.001)$, and the incidences of smoking and alcohol consumption were higher in males than in females $(P<0.001)$.

\section{Relationship between hearing threshold, clinical factors, and FRAs \\ Univariate analysis}

VAT and SAT was significantly different between sexes (Table 1). This means that sex played a part when hearing and FRAs were analyzed by regression analysis. For this reason, we reanalyzed this relationship with every regard to sex.

Regarding PTA-low, univariate analysis showed that age, height, BMI, WC, VAT, HTN, DM, and alcohol consumption correlated with hearing regardless of sex; weight correlated with hearing only in male. Regarding PTA-high, age, height, weight, BMI,WC,VAT, HTN, and DM correlated with hearing regardless of sex; alcohol consumption correlated with hearing in female and male (Table 2).

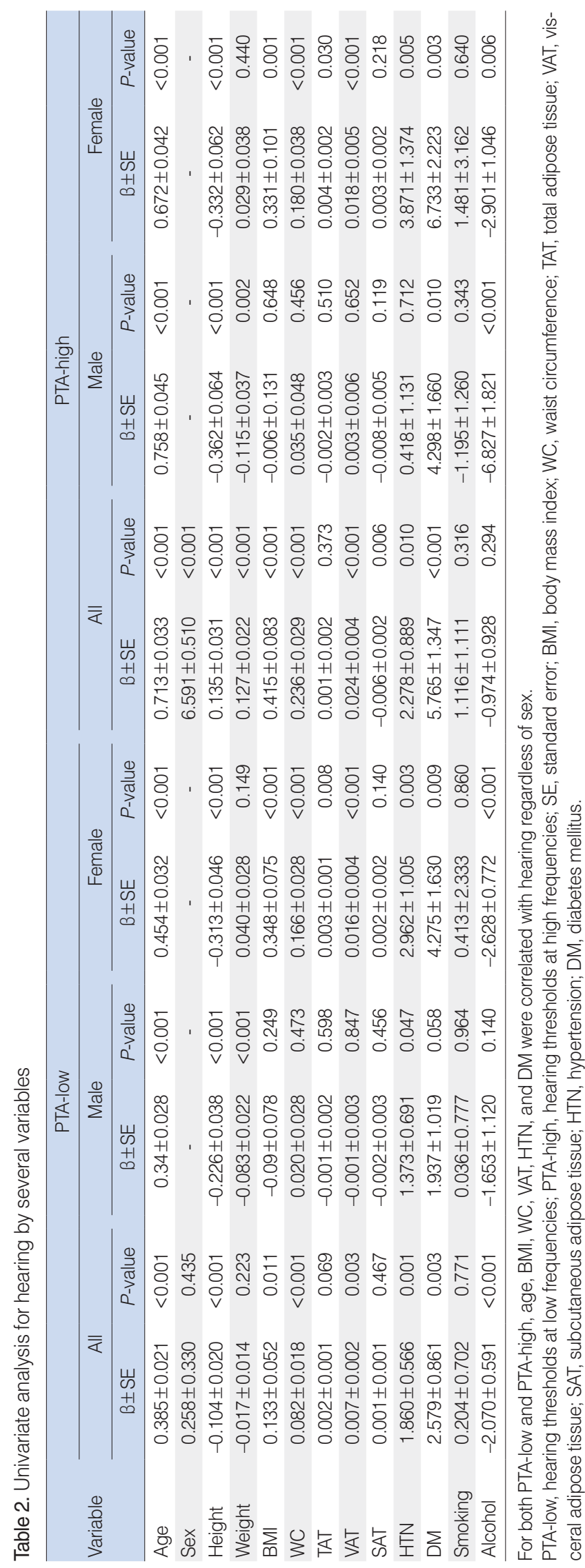


Table 3. Multivariate analyses for hearing thresholds at low and high frequencies by clinical factors inclusive of each factor relevant to obesity in males

\begin{tabular}{|c|c|c|c|c|c|c|}
\hline \multirow{2}{*}{ Independent variable } & \multicolumn{3}{|c|}{ PTA-low } & \multicolumn{3}{|c|}{ PTA-high } \\
\hline & $B \pm S E$ & $P$-value & Model $R^{2}$ & $B \pm S E$ & $P$-value & Model $R^{2}$ \\
\hline Age, height, HTN, DM, alcohol, weight & & & 0.111 & & & 0.176 \\
\hline Age & $0.338 \pm 0.047$ & $<0.001$ & & $0.734 \pm 0.074$ & $<0.001$ & \\
\hline Height & $-0.188 \pm 0.061$ & 0.002 & & $-0.287 \pm 0.109$ & 0.009 & \\
\hline HTN & - & - & & $-1.921 \pm 1.226$ & 0.118 & \\
\hline DM & $1.713 \pm 1.085$ & 0.115 & & $4.068 \pm 1.755$ & 0.021 & \\
\hline Alcohol & - & - & & $-5.307 \pm 2.122$ & 0.013 & \\
\hline Weight & - & - & & $0.108 \pm 0.065$ & 0.099 & \\
\hline Age, height, HTN, DM, alcohol, BMI & & & 0.111 & & & 0.176 \\
\hline Age & $0.338 \pm 0.047$ & $<0.001$ & & $0.735 \pm 0.074$ & $<0.001$ & \\
\hline Height & $-0.188 \pm 0.061$ & 0.002 & & $-0.196 \pm 0.096$ & 0.040 & \\
\hline HTN & - & - & & $-1.922 \pm 1.226$ & 0.117 & \\
\hline DM & $1.713 \pm 1.085$ & 0.115 & & $4.065 \pm 1.755$ & 0.021 & \\
\hline Alcohol & - & - & & $-5.316 \pm 2.122$ & 0.012 & \\
\hline BMI & - & - & & $0.326 \pm 0.193$ & 0.092 & \\
\hline Age, height, HTN, DM, alcohol, WC & & & - & & & - \\
\hline Age & $0.338 \pm 0.047$ & $<0.001$ & & $0.717 \pm 0.073$ & $<0.001$ & \\
\hline Height & $-0.188 \pm 0.061$ & 0.002 & & $-0.228 \pm 0.097$ & 0.020 & \\
\hline HTN & - & - & & $-1.908 \pm 1.227$ & 0.120 & \\
\hline DM & $1.713 \pm 1.085$ & 0.115 & & $4.063 \pm 1.756$ & 0.021 & \\
\hline Alcohol & - & - & & $-5.319 \pm 2.123$ & 0.012 & \\
\hline WC & - & - & & $0.113 \pm 0.073$ & 0.125 & \\
\hline Age, height, HTN, DM, alcohol, TAT & & & 0.111 & & & 0.173 \\
\hline Age & $0.338 \pm 0.047$ & $<0.001$ & & $0.705 \pm 0.073$ & $<0.001$ & \\
\hline Height & $-0.188 \pm 0.061$ & 0.002 & & $-0.199 \pm 0.096$ & 0.039 & \\
\hline HTN & - & - & & - & - & \\
\hline DM & $1.713 \pm 1.085$ & 0.115 & & $3.460 \pm 1.697$ & 0.042 & \\
\hline Alcohol & - & - & & $-5.369 \pm 2.126$ & 0.012 & \\
\hline TAT & - & - & & - & - & \\
\hline Age, height, HTN, DM, alcohol, VAT & & & 0.111 & & & 0.177 \\
\hline Age & $0.338 \pm 0.047$ & $<0.001$ & & $0.711 \pm 0.073$ & $<0.001$ & \\
\hline Height & $-0.188 \pm 0.061$ & 0.002 & & $-0.209 \pm 0.096$ & 0.029 & \\
\hline HTN & - & - & & $-1.946 \pm 1.225$ & 0.113 & \\
\hline $\mathrm{DM}$ & $1.713 \pm 1.085$ & 0.115 & & $4.025 \pm 1.754$ & 0.022 & \\
\hline Alcohol & - & - & & $-5.381 \pm 2.121$ & 0.011 & \\
\hline VAT & - & - & & $0.018 \pm 0.010$ & 0.061 & \\
\hline
\end{tabular}

Any among the factors relevant to abdominal fat was not correlated with PTA-low, meanwhile, all factors except TAT were significantly correlated with PTA-high. PTA-low, hearing thresholds at low frequencies; PTA-high, hearing thresholds at high frequencies; SE, standard error; HTN, hypertension; DM, diabetes mellitus; BMI, body mass index; WC, waist circumference; TAT, total adipose tissue; VAT, visceral adipose tissue.

\section{Multivariate analysis}

All factors were included in a multivariate analysis, apart from SAT and smoking, which did not show a statistically significant difference between females and males. The 5 clinical factors (age, height, HTN, DM, and alcohol consumption) and each of the FRAs (weight, BMI, WC, TAT, and VAT) were analyzed 5 times independently. That is, 6 factors, 5 clinical factors plus one FRA, were analyzed 5 times, independently.

For males, while no factor among the FRAs showed a significant difference in any analysis in PTA-low, all factors except TAT showed significant differences in PTA-high (Table 3). For females, while all FRAs showed significant differences in PTA-low, 3 of 5 factors (weight, BMI, and WC) showed no significant dif- ference in PTA-high (Table 4).

Among the clinical factors, DM showed significant differences regardless of sexes and hearing thresholds in low/high frequency. The values of $R^{2}$ were highest when VAT was included among the FRAs in multivariate analyses in PTA high and PTA low for both males and females $\left(R^{2}=0.177\right.$ and 0.284 , respectively).

\section{DISCUSSION}

In this study, we showed that the FRAs were correlated with hearing at high frequencies in males, whereas FRAs were correlated with hearing at low frequencies for females. Although there 
Table 4. Multivariate analyses for hearing by several factors including factors relevant to obesity in females

\begin{tabular}{|c|c|c|c|c|c|c|}
\hline \multirow{2}{*}{ Independent variable } & \multicolumn{3}{|c|}{ PTA-low } & \multicolumn{3}{|c|}{ PTA-high } \\
\hline & $B \pm S E$ & $P$-value & Model $R^{2}$ & $B \pm S E$ & $P$-value & Model $R^{2}$ \\
\hline Age, height, HTN, DM, alcohol, Weight & & & 0.278 & & & 0.260 \\
\hline Age & $0.484 \pm 0.062$ & $<0.001$ & & $0.806 \pm 0.082$ & $<0.001$ & \\
\hline Height & $-0.279 \pm 0.084$ & 0.001 & & - & - & \\
\hline HTN & - & - & & - & - & \\
\hline $\mathrm{DM}$ & $4.166 \pm 1.701$ & 0.015 & & $5.340 \pm 2.358$ & 0.024 & \\
\hline Alcohol & - & - & & - & - & \\
\hline Weight & $0.125 \pm 0.057$ & 0.029 & & - & - & \\
\hline Age, height, HTN, DM, alcohol, BMI & & & 0.278 & & & 0.260 \\
\hline Age & $0.484 \pm 0.062$ & $<0.001$ & & $0.806 \pm 0.082$ & $<0.001$ & \\
\hline Height & $0.312 \pm 0.142$ & 0.029 & & - & - & \\
\hline HTN & - & - & & - & - & \\
\hline $\mathrm{DM}$ & $4.171 \pm 1.700$ & 0.015 & & $5.340 \pm 2.358$ & 0.024 & \\
\hline Alcohol & - & - & & - & - & \\
\hline $\mathrm{BMI}$ & $0.312 \pm 0.142$ & 0.029 & & - & - & \\
\hline Age, height, HTN, DM, alcohol, WC & & & 0.281 & & & 0.260 \\
\hline Age & $0.464 \pm 0.063$ & $<0.001$ & & $0.806 \pm 0.082$ & $<0.001$ & \\
\hline Height & $-0.228 \pm 0.079$ & 0.004 & & - & - & \\
\hline HTN & - & - & & - & - & \\
\hline $\mathrm{DM}$ & $4.068 \pm 1.698$ & 0.017 & & $5.340 \pm 2.358$ & 0.024 & \\
\hline Alcohol & - & - & & - & - & \\
\hline WC & $0.130 \pm 0.053$ & 0.014 & & - & - & \\
\hline Age, height, HTN, DM, alcohol, TAT & & & 0.282 & & & 0.263 \\
\hline Age & $0.481 \pm 0.062$ & $<0.001$ & & $0.791 \pm 0.082$ & $<0.001$ & \\
\hline Height & $-0.218 \pm 0.079$ & 0.006 & & - & - & \\
\hline HTN & - & - & & - & - & \\
\hline $\mathrm{DM}$ & $4.614 \pm 1.670$ & 0.006 & & $5.145 \pm 2.358$ & 0.030 & \\
\hline Alcohol & - & - & & - & - & \\
\hline TAT & $0.006 \pm 0.002$ & 0.011 & & $0.005 \pm 0.003$ & 0.139 & \\
\hline Age, height, HTN, DM, alcohol, VAT & & & 0.284 & & & 0.266 \\
\hline Age & $0.471 \pm 0.062$ & $<0.001$ & & $0.780 \pm 0.083$ & $<0.001$ & \\
\hline Height & $-0.219 \pm 0.079$ & 0.006 & & $4.831 \pm 2.365$ & 0.042 & \\
\hline HTN & - & - & & - & - & \\
\hline $\mathrm{DM}$ & $4.317 \pm 1.675$ & 0.010 & & $4.831 \pm 2.365$ & 0.042 & \\
\hline Alcohol & - & - & & - & - & \\
\hline VAT & $0.015 \pm 0.006$ & 0.006 & & $0.014 \pm 0.008$ & 0.064 & \\
\hline
\end{tabular}

All factors relevant to abdominal fat were significantly related with PTA-low, meanwhile, 3 of 5 factors were not related with PTA-high.

PTA-low, hearing thresholds at low frequencies; PTA-high, hearing thresholds at high frequencies; SE, standard error; HTN, hypertension; DM, diabetes mellitus; BMI, body mass index; WC, waist circumference; TAT, total adipose tissue; VAT, visceral adipose tissue.

was not a big difference, VAT among the FRAs best described PTA-high and PTA-low for both males and females. To our knowledge, this is the first study to assess the relationship between a variety of FRAs including VAT and hearing thresholds.

The mechanisms interlinking FRAs and ARHL have not been documented clearly. Abdominal fat increase the risk of the type 2 $\mathrm{DM}$ and dyslipidemia. Regarding to type $2 \mathrm{DM}$, it was shown to cause hearing loss due to angiopathy, neuropathy, and oxidative stress and remnants of glycation end products [11]. Regarding to dyslipidemia, it was shown to causes swelling of the strial marginal layer and the outer hair cell in guinea pigs [12]. Therefore, we presume that the mechanism interlinking FRAs and ARHL might include a complicated relevance, comprising angiopathy, imbalance of redox, and neuropathy following to metabolic rem- nants of abdominal obesity. This gives explanations in part, it is still not clear if abdominal obesity could induce to ARHL.

It is unclear why the association between FRAs and ARHL differed between men and women. However, we suggest that the difference may be due to sex-related differences in the distributions of adipocytokines, hormones, and adipose tissue. Adiponectin is an adipocytokine released from adipose tissue and has a protective effect against atherogenic and inflammatory issues [13]. Concentrations of adiponectin are higher in females than in males [14]. Moreover, estrogen has been found to have a protective effect in the maintenance of the auditory system in females $[15,16]$. Finally, VAT is higher in males than females, whereas SAT is higher in females than males [17].

Our result that VAT played a role in hearing regardless of sex 
is consistent with previous studies showing that VAT is more involved in metabolic disease than is SAT [17-19]. VAT differs from SAT in several respects. First, VAT exists primarily in the mesentery/omentum and passes via the portal circulation to the liver. Second, VAT contains more glucocorticoid/androgen receptors and a greater number of inflammatory/immune cells. Third, VAT is more active in metabolism and more sensitive to lipolysis. Finally, VAT has a greater ability to take up glucose and to release free fatty acids [18].

Early intervention studies demonstrated that physical activity was helpful in reducing visceral adipose fat [20-22]. Haas et al. [23] showed that physical activity correlated with better hearing. Our study might suggest a link between these studies, given that we propose an effect of VAT on hearing.

This study has several limitations. First, this was a cross-sectional study, so we can only interpret the phenomenon, not reveal its pathophysiology. Second, the values of $R^{2}$ were similar between the analyses, and the explanatory capacity for hearing might be altered with other study samples. Third, the thresholds at extremely low $(0.25 \mathrm{kHz})$ and high frequencies $(8$ and $16 \mathrm{kHz})$ were not assessed. The hearing thresholds were tested at 4 frequencies, $0.5,1,2$, and $4 \mathrm{kHz}$, used in routine health checkups.

Our study provides further evidence that FRA is associated with ARHL in males for high frequencies and in females for low frequencies in adults aged over 40 years, and that DM and VAT in particular has major implications for hearing. Further study addressing whether weight loss with a decrease in abdominal fat would slow progression of hearing loss might be interesting.

\section{CONFLICT OF INTEREST}

No potential conflict of interest relevant to this article was reported.

\section{REFERENCES}

1. Presbycusis [Internet]. Wikimedia Foundation, Inc., c2016 [cited 2016 Jul 15]. Available from: https://en.wikipedia.org/wiki/Presbycusis.

2. Statistics Korea. Population projections for Korea: 2010-2060 (based on the 2010 census) [Internet]. Daejeon, Korea: Statistics Korea; 2011 [cited 2016 Jul 15]. Available from: http://kostat.go.kr/portal/ korea/kor_nw/2/2/6/index.board?bmode=list\&bSeq=\&aSeq=\&page $\mathrm{No}=2 \&$ rowNum=10\&navCount=10\&currPg=\&sTarget=title\&sTxt=.

3. World Health Organization Western Pacific Region. The Asia-Pacific perspective: redefining obesity and its treatment. Melbourne,Australia: International Association for the Study of Obesity; 2000.

4. Alberti KG, Zimmet P, Shaw J. Metabolic syndrome: a new worldwide definition: a consensus statement from the International Diabetes Federation. Diabet Med. 2006 May;23(5):469-80.
5. Kim SH,Won YS, Kim MG, BaekYJ, Oh IH, Yeo SG. Relationship between obesity and hearing loss. Acta Otolaryngol. 2016 Oct;136(10): 1046-50.

6. Jung DJ, Jang JH, Lee KY. Is body mass index associated with the development of age-related hearing impairment in Koreans? The Korean national health and nutrition examination survey 20092012. Clin Exp Otorhinolaryngol. 2016 Jun;9(2):123-30.

7. Hwang JH, Wu CC, Hsu CJ, Liu TC, Yang WS. Association of central obesity with the severity and audiometric configurations of age-related hearing impairment. Obesity (Silver Spring). 2009 Sep;17(9): 1796-801.

8. Kim TS, Park SW, Kim DY, Kim EB, Chung JW, So HS. Visceral adipose tissue is significantly associated with hearing thresholds in adult women. Clin Endocrinol (Oxf). 2014 Mar;80(3):368-75.

9. Goodpaster BH. Measuring body fat distribution and content in humans. Curr Opin Clin Nutr Metab Care. 2002 Sep;5(5):481-7.

10. Chung SJ, Kim D, Park MJ, Kim YS, Kim JS, Jung HC, et al. Metabolic syndrome and visceral obesity as risk factors for reflux oesophagitis: a cross-sectional case-control study of 7078 Koreans undergoing health check-ups. Gut. 2008 Oct;57(10):1360-5.

11. Maia CA, Campos CA. Diabetes mellitus as etiological factor of hearing loss. Braz J Otorhinolaryngol. 2005 Mar-Apr;71(2):208-14.

12. Satar B, Ozkaptan Y, Surucu HS, Ozturk H. Ultrastructural effects of hypercholesterolemia on the cochlea. Otol Neurotol. 2001 Nov;22 (6):786-9.

13. Lu JY, Huang KC, Chang LC, Huang YS, ChiYC, SuTC, et al.Adiponectin: a biomarker of obesity-induced insulin resistance in adipose tissue and beyond. J Biomed Sci. 2008 Sep;15(5):565-76.

14. Hwang JH, Hsu CJ, Liu TC, Yang WS. Association of plasma adiponectin levels with hearing thresholds in adults. Clin Endocrinol (Oxf). 2011 Nov;75(5):614-20.

15. Hederstierna C, Hultcrantz M, Collins A, Rosenhall U. Hearing in women at menopause: prevalence of hearing loss, audiometric configuration and relation to hormone replacement therapy. Acta Otolaryngol. $2007 \mathrm{Feb} ; 127(2): 149-55$.

16. Hwang JH, Chao JC, Ho HC, Hsiao SH. Effects of sex, age and hearing asymmetry on the interaural differences of auditory brainstem responses. Audiol Neurootol. 2008;13(1):29-33.

17. Fox CS, Massaro JM, Hoffmann U, Pou KM, Maurovich-Horvat P, Liu CY, et al. Abdominal visceral and subcutaneous adipose tissue compartments: association with metabolic risk factors in the Framingham Heart Study. Circulation. 2007 Jul;116(1):39-48.

18. Ibrahim MM. Subcutaneous and visceral adipose tissue: structural and functional differences. Obes Rev. 2010 Jan;11(1):11-8.

19. Tanko LB, BaggerYZ, Alexandersen P, Larsen PJ, Christiansen C. Peripheral adiposity exhibits an independent dominant antiatherogenic effect in elderly women. Circulation. 2003 Apr;107(12):1626-31.

20. Vissers D, Hens W, Taeymans J, Baeyens JP, Poortmans J, Van Gaal L. The effect of exercise on visceral adipose tissue in overweight adults: a systematic review and meta-analysis. PLoS One. 2013;8(2):e56415.

21. Janiszewski PM, Ross R. Physical activity in the treatment of obesity: beyond body weight reduction. Appl Physiol Nutr Metab. 2007 Jun;32(3):512-22.

22. Ohkawara K, Tanaka S, Miyachi M, Ishikawa-Takata K, Tabata I. A dose-response relation between aerobic exercise and visceral fat reduction: systematic review of clinical trials. Int J Obes (Lond). 2007 Dec;31(12):1786-97.

23. Haas PJ, Bishop CE, Gao Y, Griswold ME, Schweinfurth JM. Relationships among measures of physical activity and hearing in African Americans: the Jackson Heart Study. Laryngoscope. 2016 Oct; 126(10):2376-81. 